\section{Mechanism of Good Back-up Support With a Deep-Seated Guiding Catheter During Percutaneous Coronary Intervention}

Kensuke Yokoi, MD; Isamu Mizote, MD, PhD;

Tatsuya Shiraki, MD; Seiko Ide, MD;

Tomohito Ohtani, MD, PhD;

Shungo Hikoso, MD, PhD; Yuji Ikari, MD, PhD;

Yasushi Sakata, MD, PhD

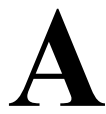

lthough the attachment site of a guiding catheter (GC) in the contralateral side of the aortic wall is important for back-up force, ${ }^{1}$ it is not clear how a deep-seated GC is positioned in the aorta. Computed tomography obtained during percutaneous coronary intervention $(\mathrm{PCI})^{2}$ showed how deep-seated GC were attached to the aortic wall.

An 85-year-old man with severe stenosis in the right coronary artery (RCA) underwent PCI. A 6-Fr JR4.0 was engaged to the RCA via the left radial artery (Figure A). To achieve good back-up support, the GC was deep-seated (Figure B). CT showed that the GC was twisted in a spiral (Figure C-E; Supplementary Movie 1).

A 66-year-old man with calcified stenosis in the left coronary artery (LCA) underwent PCI. A 6-Fr EBU4.5 was advanced from the left radial artery. The GC was deep-seated in the LCA (Figure F,G). CT showed that the GC was also twisted (Figure H-J; Supplementary Movie 2).

This imaging shows that a deep-seated GC is twisted in the aorta and that long segments are attached to the aortic wall.

\section{Disclosures}

The authors declare no conflicts of interest.

\section{References}

1. Ikari Y, Nagaoka M, Kim JY, Morino Y, Tanabe T. The physics of guiding catheters for the left coronary artery in transfemoral and transradial interventions. J Invasive Cardiol 2005; 17: 636641.

2. Yokoi K, Shiraki T, Mizote I, Sakata Y. Differences in guiding catheter positions according to left and right radial approaches. JACC Cardiovasc Interv 2018; 11: e163-e165.

\section{Supplementary Files}

Supplementary Movie 1. Deep-seated JR4.0.

Supplementary Movie 2. Deep-seated EBU4.5.

Please find supplementary file(s);

http://dx.doi.org/10.1253/circj.CJ-18-1338

Received December 13, 2018; accepted December 20, 2018; J-STAGE Advance Publication released online February 2, 2019 Time for primary review: 7 days

Department of Cardiovascular Medicine, Osaka University Graduate School of Medicine, Suita (K.Y., I.M., T.S., S.I., T.O., S.H., Y.S.); Department of Cardiology, Tokai University School of Medicine, Tokyo (Y.I.), Japan

Mailing address: Kensuke Yokoi, MD, Department of Cardiovascular Medicine, Osaka University Graduate School of Medicine, 2-2 Yamadaoka, Suita 565-0871, Japan. E-mail: yokoi@cardiology. med.osaka-u.ac.jp

ISSN-1346-9843 All rights are reserved to the Japanese Circulation Society. For permissions, please e-mail: cj@j-circ.or.jp
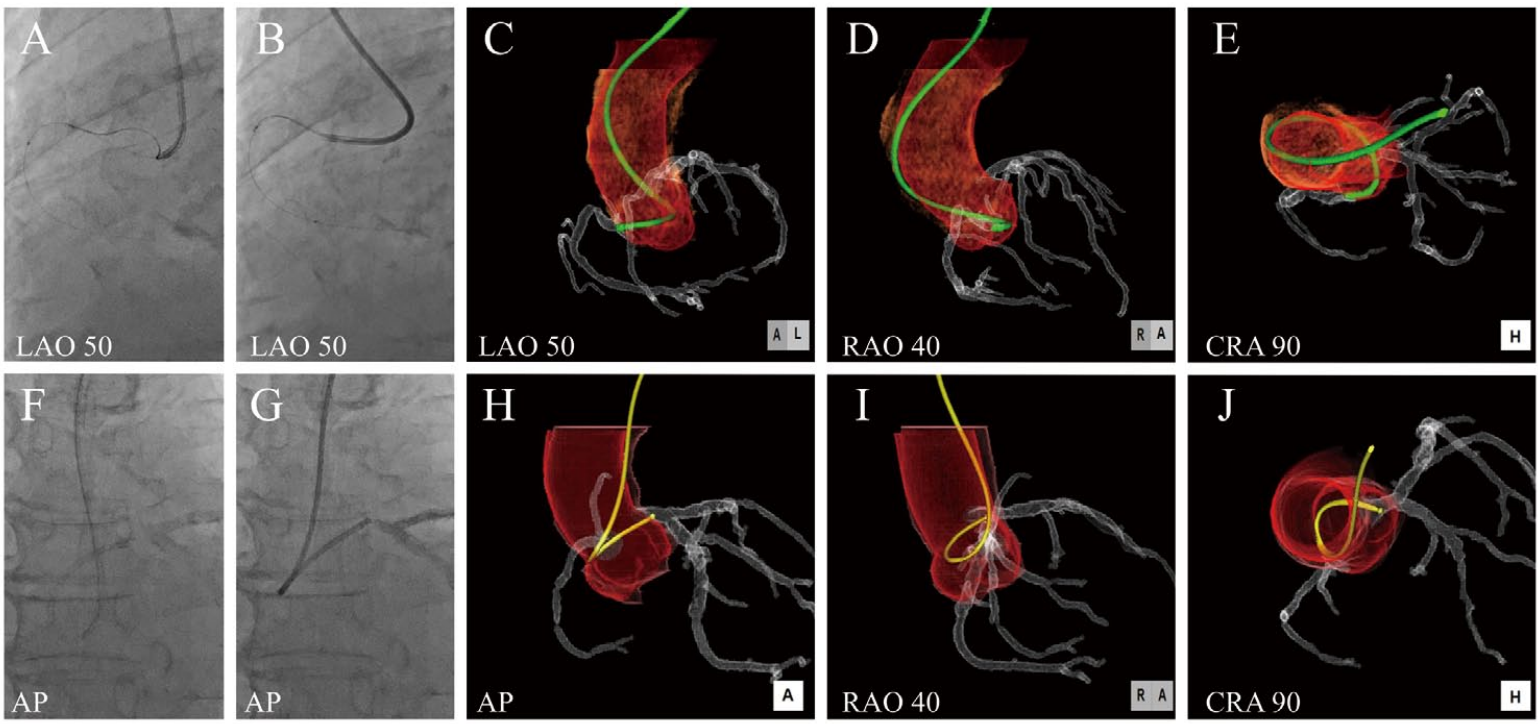

Figure. (A,B,F,G) Fluoroscopy and $(\mathbf{C}-\mathbf{E}, \mathbf{H}-\mathbf{J})$ 3-D computed tomography during percutaneous coronary intervention superimposed on ( $\mathbf{C}-\mathbf{E}, \mathbf{H}-\mathbf{J})$ preoperative imaging. (A) Normally positioned and (B) deep-seated JR4.0; (F) EBU4.5 engaged in the left coronary artery with rotation manipulation; (G) deep-seated EBU4.5. AP, anteroposterior oblique; CRA, cranial oblique; LAO, left anterior oblique; RAO, right anterior oblique. 